\title{
Regression Analysis of the Influence of Human Resource Management on Enterprise Performance
}

\author{
Chen Jing \\ Macau University of science and technology, Macau, China.
}

\begin{abstract}
Keywords: human resource management, employee satisfaction, enterprise performance, regression analysis
\end{abstract}

\begin{abstract}
Firstly, this paper constructs a model with employee satisfaction as the intermediate variable, forming the basic hypothesis of three variables: human resource management, employee satisfaction and enterprise performance; secondly, it designs the reasonable items of the questionnaire combined with the variables, and the questionnaire is issued and the survey data is recovered; finally, it integrates the data and conducts regression analysis to study the relationship between human resource management and enterprise performance, and puts forward the suggestions for human resource management.

In recent years, with the continuous acceleration of China's economic development, enterprises conform to the background of the development of the times, showing unprecedented vitality, and become an important part of China's economic construction. Talents are the core strategic resources of an enterprise and the key guarantee to improve the performance of an enterprise. This paper analyzes the influence mechanism of human resource management on enterprise performance, constructs and demonstrates the relationship mechanism between the two, which is of great significance to improve enterprise management efficiency, enhance enterprise performance, and promote the healthy and orderly development of enterprises.
\end{abstract}

\section{Problems in human resource management of enterprises}

\subsection{Imperfect human resource management system}

Enterprise human resource management system is imperfect and unreasonable, which greatly affects the efficiency of human resource management. The organizational structure system is outdated and the architecture design is not in line with the actual situation, which can no longer well support the business development; the management boundaries, responsibilities and rights between the group company and its subordinate enterprises are not clear; the management process is not efficient and simple enough to achieve high management efficiency. In terms of business, the division of labor between the group company and its subordinate companies is not clear; the business standards cannot keep pace with the times, and there is no sound, scientific and growing business assessment system; the business system is general, lack of pertinence and poor in implementation; the business implementation lacks guidance and monitoring, and cannot guarantee the real implementation of the system ${ }^{[1]}$.

\subsection{Lack of growth and promotion space for employees}

At present, whether the enterprise can provide a good development platform and growth space for employees is one of the important standards for employees to choose enterprises. Many enterprises often cause brain drain because of this problem. First of all, the enterprise's own strategic management and business plan are not clear, so it is difficult to show clear enterprise development expectations to employees, resulting in vague understanding of employees and a significant decline in their work enthusiasm. Secondly, the employee-position matching is lack of dynamic management. Or the employees change their posts frequently according to the needs of the enterprise, or they do not change their posts for many years. Failing to timely understand the matching situation between employees' expectations and positions results in job burnout and performance decrease of employees. Thirdly, they have not made a scientific career plan for their employees, and the employees lack a sense of development direction in the enterprise, so they are 
passive in their work. Fourthly, employees' vocational training and business training are insufficient, and the corresponding training courses become a mere formality and are too old-fashioned to adapt to their actual needs and growth needs. Fifthly, the enterprise lacks long-term and systematic planning for the growth and promotion of employees, does not establish a promotion system related to the positions, salaries, performance and promotion of employees, or the overall design is vague, without specific measures ${ }^{[2]}$.

\subsection{Lack of effective material incentives for employees}

The incentive mechanism of an enterprise determines whether it can effectively promote the vitality of employees and maximize the role of employees. The imperfect incentive mechanism is also one of the important reasons for brain drain. First, enterprises often lack a scientific post value system, and can't make objective value evaluation for different posts. Salary setting is arbitrary and lack of basis, which is not conducive to the retention and active work of personnel, especially core personnel. Second, enterprises generally pay according to interpersonal relationship and subjective evaluation. There is no dynamic salary matching and promotion for growing employees. Many old employees have their salary unchanged for many years, which greatly affects their enthusiasm for work and enthusiasm for learning. Thirdly, the salary structure of the enterprise is lack of vitality, where the proportion of fixed salary is too large, which leads to employees' lazy behavior and passive response to work. Fourthly, the rewards and punishments are not clear, and there is not much difference between employees with different performance in terms of merit and reward. All of the above are unscientific and ineffective performance of material incentive, which greatly affects the performance of enterprises.

\subsection{Lack of value recognition to the enterprise of employees}

Enterprise value system and enterprise culture are the important guarantee of enterprise performance, and also the source of enterprise and employee's spiritual power. Many enterprises often pay no attention to the construction of enterprise value and enterprise culture. First of all, in the process of enterprise value construction, there is no specific value refining in combination with the objectives of different stages of the enterprise, or it just simply imitates the value of other enterprises, without combining with itself to carry out a proper and distinct value orientation. Secondly, in the process of enterprise value construction, the enterprise value is often put forward by a few leaders or departments in charge of enterprise culture without listening to the opinions of more departments and employees, so the enterprise value is often only in line with the personal preferences of a few people. Third, after the enterprise value is determined, the publicity and promotion efforts are not enough, and the employees have not reached a consensus on the value orientation to form a centripetal force. Fourthly, in terms of the implementation of enterprise value, it is too abstract, sometimes it stays in slogans, and there is no supporting humanistic care and relevant projects. As a result, employees have no identity with the value and culture of the enterprise, and the whole enterprise lacks cohesion ${ }^{[3] .}$

\section{Hypothesis of the relationship between human resource management and enterprise performance}

The relevant variables of human resource management practice that affect enterprise performance mainly include attitude variables and behavior variables. In the variables based on attitude, we need to take positive and effective measures to change employees' working attitude, and then change employees' organizational behavior, so as to achieve the effective improvement of enterprise organizational performance. To change the attitude of employees, first of all, we need to improve employee satisfaction. The improvement of employee satisfaction can promote a more harmonious relationship between employees, and the overall improvement of employees' motivation, which can not only effectively reduce the turnover rate of employees, but also promote the operation of enterprises, and ultimately promote the effective improvement of enterprise performance. This paper establishes a model with employee satisfaction as the intermediate variable and enterprise 
nature, enterprise scale and enterprise operation time as the control variables. The specific model assumptions are as follows ${ }^{[4]}$.

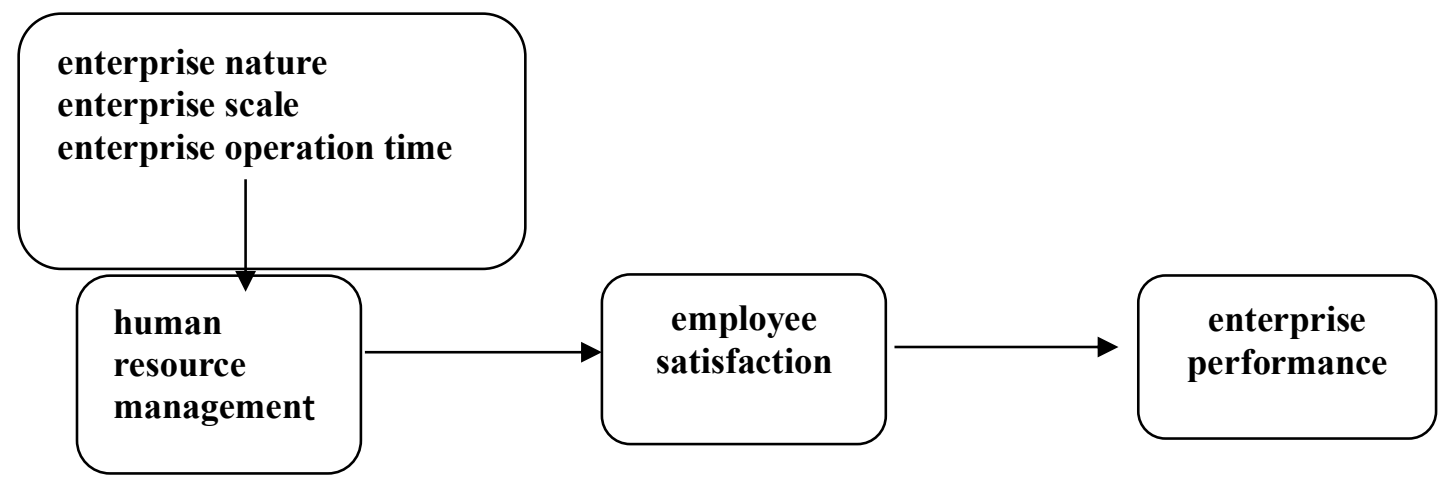

Figure 1 Model of relationship between human resource management and enterprise performance

Hypothesis 1: Human resource management is positively correlated with employee satisfaction;

Hypothesis 2: Human resource management is positively correlated with enterprise performance;

Hypothesis 3: Employee satisfaction plays an intermediary role between human resource management and enterprise performance;

Pre-control variables: Enterprise nature, enterprise scale, enterprise operation time.

\section{Regression analysis of the influence of human resource management on enterprise performance}

\subsection{Questionnaire survey}

The questionnaire includes 16 questions of human resource management, 8 questions of employee satisfaction and 6 questions of enterprise performance, a total of 30 questions. Each question is given a score from 1 to 10 as the data of the final empirical analysis. From May to June 2019, 72 enterprises were surveyed, 350 questionnaires were issued and 282 valid questionnaires were recovered.

\subsubsection{Human resource management survey}

Table 1- Statistical table of human resource management survey scores

\begin{tabular}{|l|c|c|}
\hline \multicolumn{1}{|c|}{ Question } & $\begin{array}{c}\text { Mean of } \\
\text { score }\end{array}$ & $\begin{array}{c}\text { Variance of } \\
\text { score }\end{array}$ \\
\hline X1: Job opportunities for you & 7.45 & 0.75 \\
\hline $\begin{array}{l}\text { X2: Adoption of suggestions from grassroots } \\
\text { employees }\end{array}$ & 6.89 & 0.89 \\
\hline X3: Emphasis on work experience & 8.75 & 0.74 \\
\hline X4: Payment by labor & 9.45 & 0.71 \\
\hline X5: Funds and time for personnel training & 8.45 & 0.68 \\
\hline X6: Information disclosure to grassroots employees & 7.56 & 0.68 \\
\hline $\begin{array}{l}\text { X7: Opportunities of promotion for internal } \\
\text { employees }\end{array}$ & 7.43 & 0.65 \\
\hline X8: Internal grievance opportunities for employees & 7.23 & 0.78 \\
\hline $\begin{array}{l}\text { X9: Performance assessment of employees every } \\
\text { year in employee }\end{array}$ & 6.89 & 0.63 \\
\hline $\begin{array}{l}\text { X10: Attention to performance in } \\
\text { promotion }\end{array}$ & 6.98 & 0.76 \\
\hline X11: Ability to resolve internal conflicts & 7.59 & 0.68 \\
\hline X12: Clarity of tasks assigned to employees & 7.98 & 0.63 \\
\hline X13: Span of work scope provided to employees & 7.01 & 0.62 \\
\hline X14: Implementation of senior staff management & 7.45 & 0.75 \\
\hline X15: Harmonious relationship between employees & 7.23 & 0.74 \\
\hline X16: Benefits offered to employees & & \\
\hline
\end{tabular}




\subsubsection{Employee satisfaction survey}

Table 2 -Statistical table of employee satisfaction survey scores

\begin{tabular}{|l|c|c|}
\hline \multicolumn{1}{|c|}{ Question } & Mean of score & $\begin{array}{c}\text { Variance of } \\
\text { score }\end{array}$ \\
\hline Y1: Relationship between employees & 7.56 & 0.68 \\
\hline Y2: Performance evaluation & 7.43 & 0.65 \\
\hline Y3: Task proportion & 7.23 & 0.78 \\
\hline Y4: Promotion opportunities & 6.89 & 0.63 \\
\hline Y5: Role assignment & 6.98 & 0.76 \\
\hline Y6: Welfare & 6.78 & 0.74 \\
\hline Y7: Overall management & 7.43 & 0.65 \\
\hline Y8: Training & 7.23 & 0.78 \\
\hline
\end{tabular}

\subsubsection{Enterprise performance survey}

Table 3 -Statistical table of enterprise performance survey scores

\begin{tabular}{|l|c|c|}
\hline \multicolumn{1}{|c|}{ Question } & Mean of score & Variance of score \\
\hline Z1: Profitability and asset income & 7.56 & 0.68 \\
\hline Z2: Market development and user expansion & 7.43 & 0.65 \\
\hline Z3: Employee training opportunities & 7.23 & 0.78 \\
\hline Z4: Customer satisfaction & 6.89 & 0.63 \\
\hline Z5: Market value and industry evaluation & 6.98 & 0.76 \\
\hline Z6: Operation ability & 6.78 & 0.74 \\
\hline
\end{tabular}

\subsection{Data analysis}

\subsubsection{Reliability analysis}

The Cronbach's alpha coefficients of the three groups of variables are far greater than 0.5 , indicating that all of them have passed the reliability analysis and can be used for further usability test.

Table 4 -Reliability analysis

\begin{tabular}{|c|c|c|}
\hline Reliability analysis & $\begin{array}{c}\text { Cronbach's } \\
\text { alpha }\end{array}$ & $\begin{array}{c}\text { Number of analysis } \\
\text { items }\end{array}$ \\
\hline $\begin{array}{c}\text { Reliability of data obtained from human resources } \\
\text { questionnaire }\end{array}$ & 0.814 & 16 \\
\hline $\begin{array}{c}\text { Reliability of data obtained from employee } \\
\text { satisfaction questionnaire }\end{array}$ & 0.872 & 8 \\
\hline $\begin{array}{c}\text { Reliability of data obtained from enterprise } \\
\text { performance questionnaire }\end{array}$ & 0.912 & 6 \\
\hline
\end{tabular}

\subsubsection{Factor analysis}

The KMO coefficients of the three groups of variables are all greater than 0.7 , and the significance of the Bartlett sphere test is all lower than 0.001, indicating that the data have passed the factor analysis, and the data are available.

Table 5- Factor analysis

\begin{tabular}{|c|c|c|c|}
\hline variable & \multicolumn{2}{|c|}{ Factor analysis } & Analysis value \\
\hline \multirow{3}{*}{$\begin{array}{l}\text { Human resource } \\
\text { management }\end{array}$} & KMO coefficient test & & 0.845 \\
\hline & \multirow{2}{*}{ Bartlett sphere test } & $\begin{array}{l}\text { Approximate } \\
\text { chi-square }\end{array}$ & 696.511 \\
\hline & & $\begin{array}{c}\text { Significance } \\
\text { value }\end{array}$ & 0.000 \\
\hline \multirow{3}{*}{ Employee satisfaction } & KMO coefficient test & & 0.958 \\
\hline & \multirow{2}{*}{ Bartlett sphere test } & $\begin{array}{l}\text { Approximate } \\
\text { chi-square }\end{array}$ & 622.312 \\
\hline & & $\begin{array}{c}\text { Significance } \\
\text { value }\end{array}$ & 0.000 \\
\hline
\end{tabular}




\begin{tabular}{|c|c|c|c|}
\hline \multirow{2}{*}{ Enterprise performance } & KMO coefficient test & 0.854 \\
\cline { 2 - 4 } & \multirow{2}{*}{ Bartlett sphere test } & $\begin{array}{c}\text { Approximate } \\
\text { chi-square }\end{array}$ & 411.754 \\
\cline { 3 - 4 } & $\begin{array}{c}\text { Significance } \\
\text { value }\end{array}$ & 0.000 \\
\hline
\end{tabular}

\subsubsection{Regression analysis}

The significant probabilities of the three groups of variables are all 0.001 , which confirmed that there is a significant regression relationship between every two of the three groups of variables.

Table 6 -Regression analysis

\begin{tabular}{|c|c|c|c|c|c|c|}
\hline \multirow[t]{2}{*}{ Relationship } & \multirow[t]{2}{*}{ Item } & \multicolumn{2}{|c|}{$\begin{array}{c}\text { Nonstandard regression } \\
\text { parameter }\end{array}$} & \multirow{2}{*}{$\begin{array}{l}\text { Standard } \\
\text { regression } \\
\text { parameter }\end{array}$} & \multirow[t]{2}{*}{$\mathrm{T}$} & \multirow{2}{*}{$\begin{array}{l}\text { Significant } \\
\text { probability }\end{array}$} \\
\hline & & B & Error & & & \\
\hline \multirow{2}{*}{ Human resource } & constant & 2.445 & 0.245 & & 7.004 & 0.001 \\
\hline & $\begin{array}{c}\text { Employee } \\
\text { satisfaction }\end{array}$ & 0.234 & 0.075 & 0.527 & 4.123 & 0.001 \\
\hline \multirow{2}{*}{ Human resource } & constant & 1.726 & 0.284 & & 4.512 & 0.001 \\
\hline & $\begin{array}{c}\text { Enterprise } \\
\text { performance }\end{array}$ & 0.254 & 0.099 & 0.648 & 4.425 & 0.001 \\
\hline \multirow{2}{*}{$\begin{array}{l}\text { Employee } \\
\text { satisfaction }\end{array}$} & constant & 0.732 & 0.124 & & 2.789 & 0.001 \\
\hline & $\begin{array}{c}\text { Enterprise } \\
\text { performance }\end{array}$ & 0.218 & 0.071 & 0.325 & 3.456 & 0.001 \\
\hline
\end{tabular}

The following conclusions can be drawn:

First, human resource management is positively correlated to employee satisfaction. Effective human resource management mechanisms and strategies can improve employee satisfaction to enterprises, so they will tend to serve enterprises more actively.

Second, the improvement of employee satisfaction can significantly improve the performance of the enterprise. Only when the personal value of employees is consistent with the enterprise value, and employees are willing to contribute to the enterprise, can the organizational performance of the enterprise be improved.

Third, human resource management is positively correlated to enterprise performance, and employee satisfaction is the intermediate variable of human resource management to enterprise performance $^{[5]}$.

\section{Suggestion on improving human resource management and enterprise performance}

Based on the existing problems of human resource management, combined with the empirical results of the above model hypothesis, the following practical suggestions of human resource management are put forward.

\subsection{Perfect human resource system and improve management level}

In today's society, the competition of enterprises is increasingly fierce. In order to obtain favorable competitive advantages and improve the performance of enterprises, we should establish and improve the management system of enterprises, especially the first resource - human resource management system. In practice, we should constantly perfect the rules and regulations and improve the management efficiency and accuracy. First of all, the system should be linked with the enterprise strategy, the mission of the enterprise, the values of the enterprise and the enterprise culture, and always keep the mission in mind. Secondly, we should optimize the organizational structure as soon as possible and clarify the authority of organizational management. Third, refine the business system. For different business sectors, establish management systems and processes that match the actual situation of the enterprise, so as to keep pace with the times and constantly optimize. Fourthly, establish systematic thinking, pay attention to the coordination between systems, 
so that different business sector systems can be interrelated, matched and promoted. Fifthly, strengthen management and control to ensure that the system can be implemented. For the implementation process of the system, the management and control supervision management system should be introduced to ensure that the system is implemented strictly. Sixthly, adhere to the principle of clear reward and punishment, and formulate a clear mechanism for the company's employees to reward the good and fine the bad, so as to encourage the advanced and restrict personnel, so as to further guarantee the popularity and practical implementation of the human resources system ${ }^{[6]}$.

\subsection{Establish the system of staff training and promotion and create the space for growth}

In addition to the talents deploy, human resource management should also pay attention to the cultivation of personnel and gradually improve the quality of personnel. Once an effective mechanism for talent cultivation and promotion cannot be established, it will cause the loss of personnel, affect the performance of enterprises, and is not conducive to the sustainable development of enterprises. Specifically, it should be carried out from the following aspects: first, the enterprise strategy should match the expectation of talents, and unify the development goal of the enterprise with the personal development expectation, so as to form a common force; second, pay attention to the matching of people and posts, put the right people in the right positions, so as to give full play to the role of talents to the greatest extent; third, establish a scientific and complete staff career planning system, create a training system for the management talents and business talents to develop at the same pace, and provide professional support for the growth of talents; fourth, establish an employee promotion system to ensure the continuous improvement of personnel value and rank, so as to promote the continuous improvement of enterprise performance and value [7].

\subsection{Establish an effective material incentive mechanism for employees}

Material incentive is mainly the distribution and optimization of salary and welfare. First, we should do a good job in the scientific matching of salary and posts. Establish the post value system of enterprises, and match the corresponding salary for posts with different values, so as to avoid the situation of low salary for high value posts and high salary for low value posts, resulting in the loss and negative behavior of personnel, especially for core posts. Second, a scientific salary model should be established to match employees' qualifications. Set the salary grade according to the employee's qualification instead of human relationship, ensure the dynamic adjust-ment of qualification and salary, so as to guide the employees to love their posts, pay attention to business learning, and constantly improve the business skills and professional quality; Third, adhere to fairness and openness, and ensure equal salary for the same qualification and post, and create a good atmosphere of cooperation and competition. Fourthly, we should adhere to performance-oriented. Pay attention to performance management, improve the proportion of floating salary, including performance bonus and year-end bonus. Link the income and the actual performance of employees together, so as to stimulate the vitality of employees and improve the competitiveness of employees and the enterprise performance. Fifthly, we should encourage and commend the advanced, create a healthy ecology of survival of the fittest. Give incentives such as salary increase and rank promotion to the employees with outstanding performance, so as to effectively encourage the employees with high contribution and high output.

\subsection{Strengthen the construction of enterprise value and enterprise culture}

Enterprises should attach great importance to the value and culture of enterprises, and adopt suitable methods for their construction. First of all, we should combine the strategic planning of the enterprise to decide the long-term and short-term objectives of the enterprise, and combine the characteristics of the enterprise itself to refine the unique and practical enterprise values and enterprise culture orientation. Second, we should widely collect the opinions of the subordinate companies and departments in various forms such as informal discussion, visit and prize collection, to improve the employees' sense of participation and ownership, so as to cultivate employees' sense 
of mission and belonging to the enterprise. Third, we should strengthen the publicity of enterprise culture and values. By making use of the special activities of holidays and anniversaries, closely combine the cultural concepts with employees' work busi-ness and enterprise development prospects to enhance the enthusiasm of employees, then create a strong cultural atmosphere to promote the agreement between employees and enterprise value and culture from all aspects and multiple perspectives. Fourth, in order to realize the implementation of enterprise value and culture, on the one hand, we should encourage employees to put forward constructive opinions on enterprise operation and development. When making major decisions, matters related to the interests of employees should be announced to employees to protect their legitimate rights and interests. Choosing excellent employees as models will help employees to establish benchmarking awareness under the influence of group effect, and excellent typical images will show fresh vitality and charisma, which will have a positive impact on all employees and promote the overall cohesion ${ }^{[8]}$.

\section{Conclusion}

According to the above discussion, it can be seen that good human resource manage-ment can effectively promote the steady improvement of enterprise performance. According to regression analysis, human resource management plays an important role in the overall operation and development process of the enterprise. Therefore, enterprises should improve their own human resource management level and optimize its process, strengthen management, change management concept, and establish a sound human resource security system, which will effectively promote the healthy development and operation of Chinese enterprises, play a guiding role in the steady and efficient development and construction of Chinese enterprises, and promote the development process of Chinese enterprises under the complex international and domestic economic development background.

\section{References}

[1] Package. The relationship between human resource management and enterprise performance[J]. Investment and entrepreneurship,2019, (8):176-177.

[2] Tian Libin Analysis of the Influence of Human Resource Management on the Performance of the Enterprise[J]. Commercial,2019, (37):110, 123.

[3] Zhang Jing A. Performance management in enterprise human resources management[J]. Commercial,2019, (32):18 1.

[4] Tang Guixi, Chen Lin, Chen Yang, etc. executive human resource management commitment, green human resource management and enterprise performance: the regulation of the scale of the enterprise [J]. Li Review, 2019, 22 (4):212 $\leq 224$.

[5] Lu Yanqin. The construction of enterprise human resource performance appraisal system [J]. Chiko, 2019, (22): 182.

[6] Li Qiang. The application of performance appraisal in enterprise human resource management [J]. Business, 2019, (32): 118.

[7] Luca Cacciolatti, Ainurul Rosli, José L. Ruiz-Alba, Jane Chang. Strategic alliances and firm performance in startups with a social mission[J]. Journal of Business Research,2020, 106.

[8] Etriya Etriya, Victor E. Scholten, Emiel F.M. Wubben, S.W.F. (Onno) Omta. The impact of networks on the innovative and financial performance of more entrepreneurial versus less entrepreneurial farmers in West Java, Indonesia[J]. NJAS - Wageningen Journal of Life Sciences, 2019, 89. 